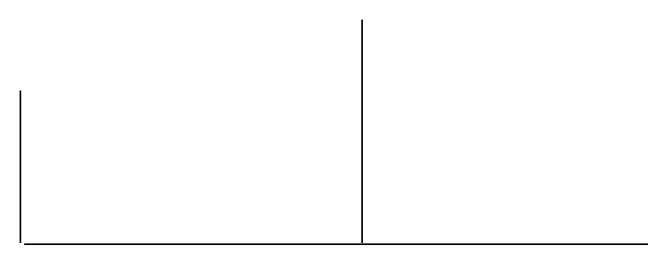

Rev. Latinoam. Psicopat. Fund., VII, 1, 40-62

\title{
Um psicótico ajuizado: incidências da psicanálise no tratamento psiquiátrico da psicose
}

\author{
Eduardo de C. Rocha \\ Francisco Leonel F. Fernandes
}

\begin{abstract}
O presente trabalho discute em que aspectos a psicanálise pode ser relevante no campo da saúde mental e da psicopatologia. Conduzimos nossa discussão com base em um tratamento "bem-sucedido" para, a seguir, tomar em consideração as propostas clínicas e de gestão da "doença mental" quer informadas pelo sociologismo quer pelo biologismo da psiquiatria contemporânea. Interrogamos a curiosa aliança entre essas apreensões clínicas sob o prisma da exigência em comprometer os resultados do tratamento da loucura a uma inserção pacificada do sujeito a formas mais tolerantes de gestão social - ambientes artificiais de convivência -, isso em detrimento de uma escuta efetiva do dizer psicótico, na qual se neutraliza a verdade que esse dizer pode veicular. Nossa orientação é a de que a psicanálise é uma discursividade comprometida em recolher e fazer reverberar esse dizer da loucura na ordem do discurso.
\end{abstract}

Palavras-chave: Psicose, psiquiatria, saúde mental, reforma psiquiátrica 


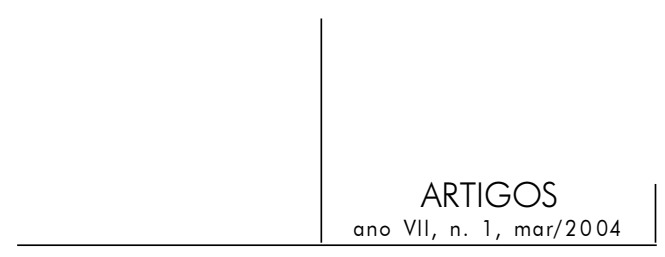

\section{Introdução: um psicótico "normal"}

Temos acompanhado nos últimos anos o engajamento clínico e teórico de vários colegas que têm procurado encontrar um fio justo por onde fazer passar de forma produtiva um diálogo entre a psiquiatria e a psicanálise. O prof. João Ferreira da Silva Filho, diretor do Instituto de Psiquiatria da UFRJ, apontou no XIX Congresso Brasileiro de Psiquiatria, que os psicanalistas recolocam a loucura em sua dimensão de linguagem, e espera que os psiquiatras não deixem de reconhecer que o louco é um ser de linguagem, "um falante soterrado pela própria fala" (Silva Filho, 2001). Se não podemos recolher uma quantidade extensa de trabalhos nessa direção, no entanto já encontramos alguns que procuram estabelecer os termos envolvidos nessa questão, por um lado, e outros que avançam numa abordagem psicanalítica de diversos quadros clínicos de psicose, contribuindo para iluminar as peculiaridades e dimensões desse soterramento subjetivo da própria linguagem. Ao final, apresentamos uma breve lista de alguns desses trabalhos que nos serviram de referência e esperamos que os pontos que aqui abordamos sirvam de contribuição para consolidar o terreno de uma clínica da loucura menos submetida aos ideais cientificistas modernos.

Neste trabalho, debateremos o tema do tratamento da psicose. Para tanto, iniciamos com a narrativa de fragmentos de um caso de um sujeito psicótico que se trata há muito tempo, em torno de dez anos, e que, até o momento, parece ser um tratamento bem-sucedido.

É desses casos que, dificilmente, alguém diria tratar-se de um psicótico, pois ele não exibe nenhum signo ostensivo de um quadro clínico como esse. Sabemos de sua situação em razão de sua história e do fato de sua confiança no tratamento, já que vez ou outra, por exemplo, ele nos notifica estar observando que voltou a conversar com Deus por intermédio dos meios de comunicação (televisão, rádio, 


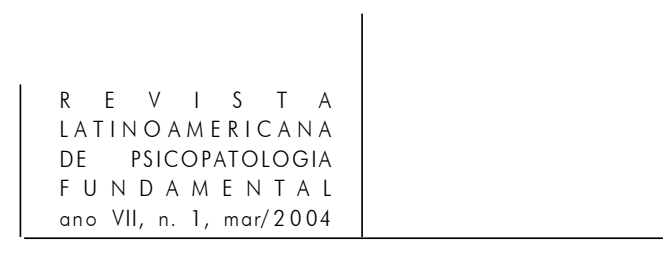

jornais, outdoors, etc.), além de outros fenômenos dessa ordem. Ele diz que, quando observa tais coisas nele, é porque é hora de conversar mais com o analista ou de aumentar um pouco a dose do medicamento. Convenhamos que este é um tipo raríssimo de sujeito psicótico: lúcido e responsável de sua situação. Não é de modo algum um paciente comum, desses nos quais a contrariedade com relação a qualquer iniciativa terapêutica é um traço bastante evidente.

No entanto, quando esse sujeito chegou até nós, sua situação era gravíssima. Ele vinha de uma tentativa séria de suicídio, no bojo de manifestações muito agressivas, recheadas de passagens por atos graves, tais como agressão física aos familiares e amigos. Chegamos a pensar que se tratava de um quadro clínico insidioso de esquizofrenia, no qual um desfecho de demência ou suicídio não é raro. Mas o caminho que o sujeito tomou foi outro. Ele tinha uma questão, bastante freqüente nesses casos, que girava em torno do que é ser homem ou ser mulher. Durante anos, ele se interrogou sobre as diferenças em pertencer a uma ou outra classe. Havia sessões em que ele simplesmente nos trazia listas das diferenças que observava. Eram detalhes ínfimos, coisas como a maneira como homens ou mulheres cruzam as pernas, as cores das camisas, como penteiam os cabelos, etc. $\mathrm{Na}$ medida em que esse trabalho avançou, houve um arrefecimento das manifestações psicóticas. As vozes cessaram, as perseguições se abrandaram e ele foi se firmando no mundo "normal". Arrumou uma namorada, completou um curso superior, casou-se, teve filhos e, finalmente, colocou-se na linha de sucessão da empresa familiar.

Seu tratamento não foi linear. Após o surto inicial, ainda na adolescência, ele o interrompeu algum tempo, logo após o início de um namoro. Retornou por ocasião do casamento, interrompendo logo a seguir à sua realização. Retornou por ocasião da gravidez do primeiro filho, mas interrompeu pouco tempo depois do nascimento para outro retorno quando a perspectiva de seu crescimento na firma do pai colocou-o defronte a certos problemas de posicionamento nas relações profissionais. A indicação de suas sucessivas retomadas e abandonos é clara: vem ter ao analista por ocasião de passagens simbólicas fundamentais. Poderíamos dizer que sua "estabilidade" não está tanto num delírio acabado, mas em algo possível a partir de seu recurso ao que aqui designamos por análise e também ao psiquiatra.

O que se passa nessa análise? Num primeiro tempo são as listas. A cada vez, trata-se de fazer listas, um exaustivo recenseamento sobre o tema que o aflige na ocasião: o que é casar-se, ser pai, dirigir uma empresa. Ao lado desse tipo de interrogação, de resto tão comum e de modo algum exclusiva de sujeitos psicóticos, ele desenvolve uma reflexão sobre sua relação com a religião e com Deus. É nesse contexto que podemos observar muito de perto suas passagens propriamente psicóticas. Ele diz saber que, por exemplo, a mensagem de uma 


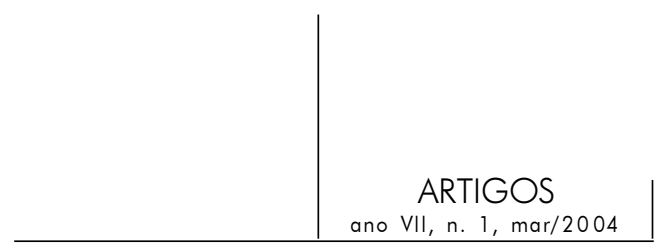

propaganda num outdoor em que a imagem de uma mão apontando e um "você" em letras garrafais não se refere a ele em particular, mas que não pode evitar sentir-se acusado. Ele chega a dizer que mais um pouco deixa de sair na rua por conta de tal propaganda. Mas em razão do fato de entender que tal coisa é loucura, ele vai fazer o que tem de fazer, isto é, vai trabalhar como qualquer pessoa comum. Em outro momento, ele nos fala de sua vontade de pular no trilho do metrô; por vezes a vontade não é sua, é a voz lhe dirigindo esse comando; outras vezes, é um cidadão qualquer que lhe dirigiu um olhar estranho na bilheteria e que, telepaticamente, envia-lhe esse comando. Quem sabe seja Deus ou o diabo disfarçados. A seguir, ele ri, não entende como de repente essas bobagens se tornam tão reais, a ponto de ele pensar em cometer uma loucura.

O curioso nisso tudo, e é uma de suas perguntas, é que essas "maluquices" todas não parecem ter qualquer conexão com seus problemas de vida. Como as dificuldades no trabalho, por exemplo. Em relação aos problemas de vida, ele consegue adotar as posições as mais sensatas, mas ainda assim essas manifestações psicóticas o atingem de maneira pontual com uma certa freqüência. Ele oscila entre entender esses fenômenos como algo orgânico, sobre o qual não tem e nunca terá qualquer controle - nesse caso terá de tomar remédio a vida toda - ou como algo devido à sua personalidade, pelo fato "de ser muito acelerado", de qualquer problema, por menor que seja, tomá-lo por inteiro, a ponto de fazêlo pensar sobre o problema até a exaustão, algumas vezes inclusive sacrificando suas noites de sono. Nesse caso, ele deve encontrar um meio de acalmar-se, de entrar em paz. Ele aponta muitas vezes seu tratamento conosco como uma possibilidade de considerar seus problemas com mais calma.

Nesse sentido, seu tratamento tem sido bem-sucedido! Mas para nós isso suscita tantos problemas quanto os tratamentos mal-sucedidos. Por quê? Porque o êxito do tratamento pelo simples fato de ser êxito não apresenta as razões pelas quais ele é bem-sucedido. Não deixa de ser um devaneio delicioso imaginarmos que tal situação é resultante de nosso talento excepcional para cuidar de psicóticos. Mas as questões se impõem. Não fazemos no caso nenhum esforço exuberante, não temos nenhuma compreensão, difícil ou complexa, que justifique o desenvolvimento, até o momento, feliz do caso. Quando ele chegou até nós, ainda no primeiro surto, fomos construindo uma boa relação, com um colorido amistoso, com intervenções muitas vezes guiadas pelo mais elementar bom senso e isso, ao que parece, foi suficiente para que ele se pusesse a trabalhar. Ele montou uma espécie de teoria de sua loucura a partir da qual a administra. Ele se diz, como já mencionamos, muito nervoso e que, diante de questões banais e triviais para a maioria das pessoas, põe-se a pensar de uma forma absurda, sem cessar, sem interrupções. Essa intensa atividade acaba por conduzi-lo a um diálogo direto com Deus e os anjos. Então, é o caso de ele desenvolver téc- 


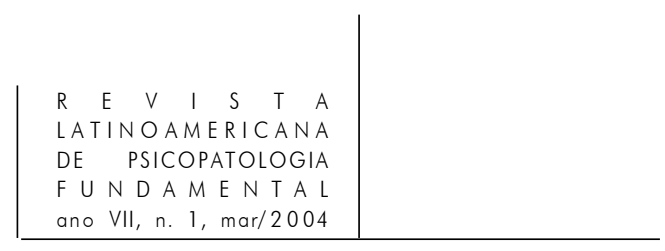

nicas de desligamento dessa obsessão, para evitar sair do ar, e se informar nos assuntos de Deus, para ir respondendo às perguntas sem a presença efetiva do Todo-Poderoso, por meio de uma religião "oficial". Enfim, sua teorização vai no sentido de ele estabelecer a boa distância e, nos parece, é para isso que sua análise serve: ela é um cenário relativamente neutro e amistoso no qual ele pode desenvolver isso. Parece-nos ser por essa razão que ele sempre nos procura nos momentos cruciais de sua vida, naqueles em que ele não consegue limitar o fluxo de seus pensamentos. Agora, por que isso dá certo? Por que a análise não o coloca mais nervoso ainda do que diz ser? É como se ela lhe permitisse formular algumas coisas que lhe poupam do excesso de pensamentos - nesse sentido ela o acalma.

Mas isso é o que ele diz. Essa é sua teoria. Nossa questão é como devemos entender isso tudo baseando-nos na psicanálise, em seus conceitos. Além do laço que ele estabeleceu conosco, existem dois pontos importantes que devemos sublinhar, dois elementos que, sem dúvida, são decisivos no fato de esse sujeito poder estar bem situado na vida e na vida ordinária. Um é sua resposta aos medicamentos: ele responde muito bem aos medicamentos e se submete à disciplina de tomá-los todos os dias sem problemas. Outro ponto é a sua relação com a família. Mesmo após a manifestação mais aguda, ainda na adolescência, quando vários especialistas foram unânimes quanto ao diagnóstico de esquizofrenia paranóide, seus familiares nunca lidaram com ele como se fosse um inválido. Seus parentes trataram a manifestação psicótica como um episódio, uma fase. Seu pai mesmo não hesitou em colocá-lo na empresa quando observou que seu comportamento não mais exigia cuidados maiores. O apoio da família foi irrestrito e, sobretudo, não teve a ambivalência tão comum aos familiares nesses casos. Nesse momento, não arriscamos nenhuma hierarquização em relação a esses fatores, no sentido de estabelecer qual o mais importante, qual condiciona os demais, bem como qual é a articulação entre eles. Apenas ressaltamos algo que pode ser generalizado: é raro a um psicótico poder levar sua vida integrado do mesmo modo que o sujeito do qual estamos falando, sem que os fatores acima apontados se apresentem. Dos três fatores, justamente a análise é o mais dispensável. Com efeito, muitas vezes vemos a função que um analista pode exercer sobre tais pacientes diluídas na figura do psiquiatra, de algum amigo, de um professor. Eis um ponto que discutiremos mais adiante, qual(is) a(s) especificidade(s), de um lado, do encontro de um analista com um psicótico e, de outro, do encontro dos psiquiatras com os analistas. Este último ponto pode ser circunstanciado de várias maneiras: dos grandes analistas que foram psiquiatras; da importação de conceitos analíticos para fundar uma psiquiatria dinâmica; da própria posição da psicanálise junto à psiquiatria como uma certa "especialidade" médica; finalmente, do que podemos entender a respeito da 


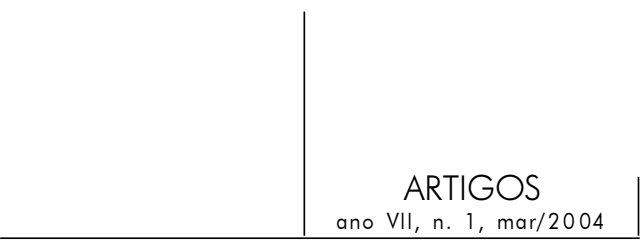

relevância da psicanálise no cenário da psiquiatria atual - sem dúvida a questão central de nosso artigo.

\section{A situação da psiquiatria}

Há vários aspectos que gostaríamos de destacar relativamente ao tratamento do paciente referido anteriormente. Há uma enormidade de casos endereçados aos hospícios, delegacias e congêneres com um prognóstico bastante sombrio. Por outro lado, sabemos também que contribuições seminais para a cultura, para a humanidade foram realizadas por indivíduos psicóticos. Dois temas se impõem. Um, o que justifica um psicótico ser tratado; outro, o que pode ser avaliado como êxito ou fracasso nos tratamentos dispensados aos psicóticos. Em geral, é fácil para um sociólogo ou antropólogo demonstrar o viés que os psiquiatras adotam em seus critérios de diagnóstico e de avaliação. Isso causou um grande impacto nas décadas de 1960 e 1970. Afinal, se demonstrava que as ferramentas dos psiquiatras e analistas não passavam de preconceitos sociais naturalizados, travestidos numa linguagem técnica automistificadora. Mas o fato foi que, apesar das denúncias, não se conseguiu nenhum outro tipo de resposta efetiva para a maioria dos casos de psicose fora da psiquiatria. É certo que os hospícios e as internações diminuíram significativamente. Mas as razões para isso não estão diretamente ligadas ao fim dos preconceitos sociais. Simplesmente trocou-se o muro de concreto dos hospícios pelo muro da bioquímica, cada dia mais eficaz e refinada quanto aos seus efeitos visados e colaterais. Se os filósofos, na década de 1960, quando interrogavam a psiquiatria, buscavam pressionar na direção de um novo laço da sociedade com a loucura, que não a exclusão, hoje eles ficariam estarrecidos, pois não deixa de ser uma ironia ter sua luta encontrado a solução nas drogas, tal como é sustentado pela psiquiatria atual. É fato a não existência de abordagem da psicose que tenha conseguido escapar da prescrição de medicamentos no tratamento. Mesmo as iniciativas como os dispositivos de Atenção Diária (CAPS, NAPS, Hospitais-Dia), inovadoras sob vários aspectos, não escapam dessa injunção. Sem o apoio dos medicamentos, da eventualidade das internações curtas - nem sempre tão curtas assim - e mesmo de alguém que pague o preço de bancar essas decisões com sua autoridade, seria difícil sustentar esses trabalhos alternativos ao hospício.

Entretanto, nossa questão não é o uso ou abuso dos medicamentos - o que seria uma tolice, aliás. Nossa discussão diz respeito ao que pode dar conta da psicose e de que modo. É óbvio que o simples "re-arranjo" de variáveis sociais não dá conta da psicose, assim como também é óbvio que os medicamentos con- 


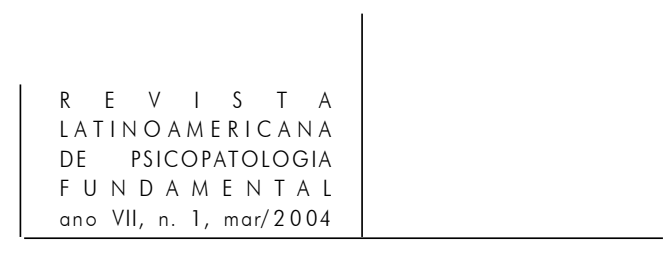

duzem em geral a um apaziguamento. Nos casos que vão um pouco mais longe, em geral observamos a presença de uma intervenção não inteiramente situada no plano da funcionalidade pragmática da linguagem e dos códigos que informam o acesso ao campo da realidade. É esse fato que está diretamente ligado ao que podemos denominar como o real da psicose - e a questão é como podemos discriminá-lo. Aqui, o instrumental sociológico, ou qualquer outro referenciado ao social, não discrimina o que está em questão. Com efeito, para qualquer cientista social desejoso de fazer sucesso fácil, basta tomar para análise um prontuário psiquiátrico. Uma ampla lista de categorias preconceituosas estarão ali "elencadas". Esses equívocos dizem algo da verdade que cerca a psicose. É que todas as descrições da psicose são comportamentais. A psicose é notada na interação social, no plano das verbalizações do dia-a-dia, dos hábitos. O psicótico inclusive não deixa de se referir a essa interação, ele reage a essa interação. O paciente que examinamos anteriormente, em seu surto, defendia seu direito de andar pelas ruas. Os pais, confusos, acataram, até porque ele fez uma defesa implacável desse seu direito. Foi um grande susto para todos quando ligaram da delegacia informando-lhes que alguém do metrô o impedira de se jogar nos trilhos. O paciente, a essa altura, dizia que isso era um teste de Deus, que ele não iria morrer. Os pais correram um grande risco, pois só puderam se dar conta da loucura do filho quando ele proferiu esses absurdos semânticos óbvios. E, infelizmente, esse fato na essência é intransponível. Não podemos intervir sobre quem quer que seja sob alegação de que mais adiante fará uma passagem ao ato, embora até hoje inúmeros psiquiatras sustentem internações sob essa razão. O ponto básico é que as manifestações subjetivas são "indecidíveis" num largo espectro quanto à estrutura daquele que fala ou age. E mesmo que o sujeito seja completamente louco, isso não justifica que nossa prevenção ou, conforme o caso, proteção em relação a ele exceda certos limites.

Contudo, em algum momento se faz necessário intervir. Esforçamo-nos para que seja no momento adequado. Está em jogo aí uma autorização dada à psiquiatria, cuja negociação de seus limites - móveis, evidentemente - faz parte do próprio tratamento. No caso acima, não tivemos dúvida quanto à imediata internação. Mas qual é o momento "adequado"? Aqui, a experiência nos fornece evidências, mas não critérios. A evidência nos é dada pelo fato de o sujeito romper com valores discursivos que formam os alicerces de nossa apreensão da realidade: 1) a vida é um "bem" que devemos sempre nos esforçar por preservar; 2) não é razoável que Deus se comunique diretamente com alguém solicitando-lhe absurdos, como atentar contra a própria vida; 3 ) somos mortais e certas injunções do mundo físico produzem efeitos irreversíveis, por isso não é razoável que alguém sobreviva ao choque de um trem; 4) aceitando-se os argumentos acima, tem-se que a ruptura com os valores discursivos (principalmente semânticos 


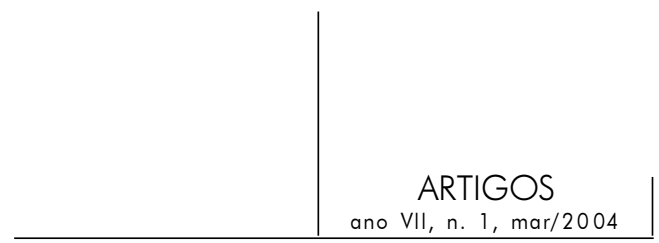

nesse caso) torna-se patente, para além do que qualquer um pode admitir como razoável. Eis aí uma evidência da oportunidade de intervir. Quem, em sã consciência, defenderia o direito de alguém se atirar nos trilhos do metrô com objetivo de realizar uma prova proposta por Deus? Isso é loucura. Mas e quanto a critérios? Será que poderíamos ter intervindo antes?

Responder a uma pergunta como essa é tomar uma posição em relação à clínica psiquiátrica. Tomar uma posição principalmente em relação à desistência da clínica surgida no bojo da crítica aos clássicos, em nome dos direitos sociais dos doentes mentais, como se as duas coisas, clínica e direitos sociais, fizessem parte de um mesmo campo de discurso, embora em lados opostos. Qual foi a conseqüência de se enfraquecer, por exemplo, as exigências quanto ao diagnóstico? O argumento era o de que o diagnóstico psiquiátrico é discricionário, valia como um rótulo que operava no fortalecimento de um processo de exclusão social. Argumentava-se também que, do ponto de vista médico, era uma inutilidade, já que o diagnóstico de doente mental levaria qualquer um a receber o mesmo tratamento, o que significava, na maioria dos casos, ser internado numa instituição asilar. Essa foi a primeira etapa do processo de crítica à psiquiatria clássica, promovida principalmente pelos desdobramentos e reflexos da antipsiquiatria. Paralelamente à politização da psiquiatria - que de fato chegou a estabelecer uma relação entre alguns sintomas psiquiátricos com a própria institucionalização, o que não foi sem importância, embora visasse à própria psiquiatria como clínica -, desenvolvia-se a psiquiatria médica, a clínica dos transtornos, a clínica americana dos DSM, isto é, dos métodos de diagnóstico estatístico. Com isso, "limpava-se" a psiquiatria da ideologia, da filosofia, da política, e a encerrava no campo "científico". A clínica ficava assim dependente dos neurotransmissores e dos medicamentos que agiriam sobre eles. A doença mental deixa de ter qualquer relação com uma psicopatologia discursiva (o fundamento próprio de uma psicopatologia autônoma é posto por terra), a menos, é claro, que o discurso psicótico sirva apenas para demonstrar o funcionamento cerebral e se transforme em transtorno, isto é, fruto de uma economia especificável da transmissão "neuronal". A partir daí, as entrevistas passam a ser substituídas por questionários que, por sua vez, alimentam quadros estatísticos. O clínico tradicional visava ao fundamento, à estrutura psicopatológica que daria conta do quadro geral. Havia uma entidade, ou um transtorno fundamental ou primário, e então os secundários. A clínica dos DSM parcializa, pulveriza esse escrupuloso clínico tradicional. O que expande também o campo dos medicamentos.

Assim, o enfraquecimento das exigências quanto ao diagnóstico favoreceu uma generalização completamente indevida do uso de medicamentos psiquiátricos. A psiquiatria como que se torna cúmplice de um processo de drogadicção generalizada, em que qualquer reunião espúria de traços clínicos pode vir a se 


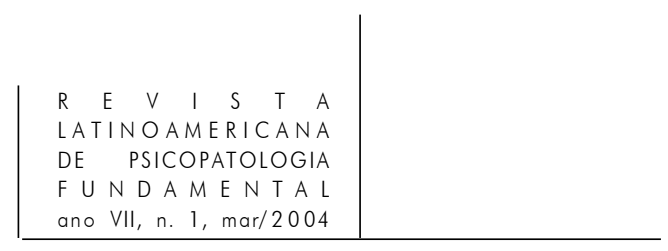

tornar equivalente a tal ou qual indicação medicamentosa. Recentemente, alguém na revista Veja propôs o "mau-humor" como uma dessas síndromes para a qual é adequado o uso de antidepressivos! Mas mais importante do que isso foi a diluição da psicose no mundo dos comportamentos possíveis. Ao desistir de identificar a psicose como fato de discurso, a psiquiatria abole essa referência, arduamente conquistada, de recolher uma produção no limite do discurso que é Outra em relação à Razão. A referência que todos temos de uma produção "linguageira", de uma subjetividade no limite do discurso da razão, perde-se.

As denúncias contra os diagnósticos e contra o trabalho de identificação das psicoses, por exemplo, funcionam como críticas que confundem o necessário com o contingente e jogam a criança fora junto com a água suja. Não há relação entre identificar a psicose, tratar o sujeito em função do seu diagnóstico dentro das referências clínicas adequadas e marginalizá-lo do ponto de vista social. A marginalização imposta ao louco, pelo fato de ser louco, não é consequiência de seu diagnóstico psiquiátrico; é consequiência, isso sim, da relação que uma dada sociedade tem com a loucura. Ora, é justamente essa questão que desaparece a da relação que a sociedade tem com a loucura - quando se desiste de identificar a loucura. Tratar a loucura como um comportamento qualquer, desconhecê-la, é tão ou mais violento que abandonar os loucos nos asilos - até porque esse abandono não deixa de acontecer sob o rótulo de novas marcas e modos. Não podemos deixar aqui de afirmar nossa tese quanto à reforma psiquiátrica: esta visa intervir sobre uma certa relação da nossa sociedade com a loucura, o que não quer dizer negá-la, nem desconhecê-la. Para nós, a reforma não é simplesmente um puro e natural avanço da categoria de cidadania; ela é, sobretudo, um como essa iniciativa que visa acolher a loucura, mediante dispositivos adequados, pode se fazer valer na cidade.

É importante lembrar que a psiquiatria tem uma função social que não diz respeito apenas aos loucos, diz respeito também à sociedade. Preconceito ou não, o fato é que, do mesmo modo que se julga se o ato de alguém é criminoso ou não, julga-se também se alguém é louco ou não. O mundo moderno reservou aos médicos, em especial à psiquiatria, a tarefa de recolher não só o discurso sobre a loucura como também a própria produção louca dos loucos. A psiquiatria, nesse sentido, é mediação social, ela é um fórum importante no qual se discute e se decide de uma maneira concreta, sob a égide de certos princípios (não necessariamente e exclusivamente científicos), as noções e os atos que uma sociedade aciona em relação à loucura. Vale dizer, a psiquiatria deve responder por sua função, pois, se ela se demite dessa tarefa, ela se extravia num de dois extremos: 1) a função de polícia, de repressão, de escamotear toda e qualquer ruptura social por meio dos fármacos e em nome da funcionalidade do sistema social; ou 2) a caridade, a assistência social, em que a loucura é mantida no 


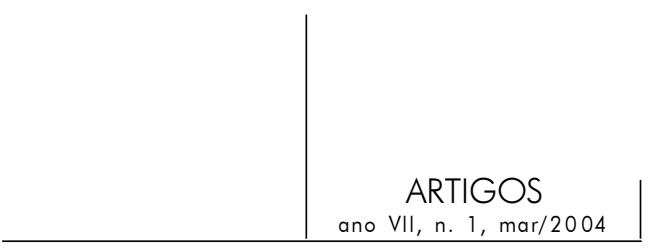

exterior, sem interrogar a sociedade na qual emergiu, assimilada que foi nas diversas figuras de vítima.

Pensamos ser no contexto dessa discussão que a relação entre a psicanálise e a psiquiatria assume uma enorme importância. É nossa aposta, psicanalistas que somos, que a psicanálise pode introduzir uma linha de força no campo da psiquiatria que pode deslocá-lo quanto a essa destinação que lhe parece estar cada vez mais reservada: a de desautorizar a loucura, reduzindo-a às disfunções do cérebro e a injunções sociais, e não à posição do sujeito como índice do real da linguagem na determinação da subjetividade. Dissemos pode porque não encontramos no cenário mundial da psiquiatria, e mesmo no da medicina, muitos elementos que nos animem. Ao contrário, os médicos em geral se distanciam cada vez mais da subjetividade de seus pacientes, e os psiquiatras seguem pela mesma via. A "subjetividade" que tem acolhida social é aquela já psicologizada nos termos cognitivistas. À guisa de verificação desse interesse, basta lembrar que os congressos de psiquiatria, atualmente, se assemelham mais a feiras em shoppings do que a debates científicos.

\section{Psicanálise e psiquiatria}

É certo, como já assinalamos, que a demanda dirigida à psiquiatria é uma demanda social, em geral uma solicitação de proteção diante da iminência da passagem ao ato por parte do suposto psicótico. Isto é, não se intervém sobre um psicótico enquanto sua produção está referida à cultura, por mais excepcional e singular que seja essa produção - nem Cantor nem Gödel, por exemplo, freqüentaram hospícios por conta de seus respectivos trabalhos revolucionários no campo da matemática e da lógica. Eles foram ao encontro do psiquiatra em razão de narrativas e atos classificados por este estamento da medicina como loucos. Mas não foi a medicina quem foi atrás deles; foram eles próprios, seus colegas, familiares e vizinhos que viam em seus respectivos atos e narrativas uma disrupção em relação a certos valores, que os conduziram à psiquiatria. Portanto, a intervenção sobre a psicose está bastante distante de uma demanda dirigida ao analista. Ela é uma demanda posta por alguém, em geral próximo do psicótico podendo ser ele próprio, embora mais raramente - pelas mais diversas razões, enfim, dirigida para a sociedade, representada pelo psiquiatra diante da ameaça de passagem ao ato e da "insuportabilidade" das manifestações concretas da loucura. Ocorre que o psicanalista pode estar na cena por fazer parte do quadro funcional da instituição que recebe essas demandas, na figura de um médico, psicólogo, enfermeiro ou assistente social. 


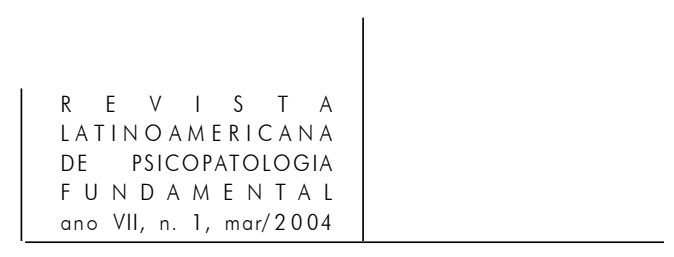

Esse ponto é crucial pela simples razão de que o psicanalista toca em aspectos presentes na inauguração da psiquiatria. Em geral, os textos críticos que tratam da história da psiquiatria situam um agenciamento que se inicia no poder: uma necessidade do poder, visando preservar sua funcionalidade mediante mecanismos "segregatórios". Esses trabalhos foram muito importantes no contexto das décadas de 1960 e 1970, já que nesse período alcançava seu ápice entre nós, a organização asilar do tratamento da loucura, promovida por um discurso médico, que justamente desconhecia de maneira radical a dimensão social de sua operação; precisamente esses trabalhos vão colocar para a psiquiatria essa dimensão por ela ignorada, mas que, no entanto, está em sua constitiuição mesma como disciplina médica - como dissemos, a demanda dirigida à psiquiatria emerge com toda evidência no campo social. Contudo, num segundo tempo, essas críticas, e principalmente o mecanismo de denúncia, passa a ter a pretensão de se constituir em tratamento, como se a simples denúncia pudesse por si só substituir os atos propriamente psiquiátricos. A crítica então fundamental para apresentar para a própria psiquiatria suas determinações sociais passa a se colocar, indevidamente, como procedimento terapêutico. O impasse então é total, já que essa suspeição incidente sobre a psiquiatria não é de modo algum compartilhada pelos atores concretos que se confrontam diretamente com a loucura (seus pais, amigos, vizinhos, parentes, patrões, etc.) - gente muito pouco permeável às considerações críticas deslocadas de sua efetividade própria, pois é claro que eles se dão conta que não é suficiente a denúncia de maus tratos para que o delirante abandone seu delírio. E eles não deixarão de fazer alguma coisa para encaminhar suas dificuldades. Vale dizer, a demanda emersa da loucura não pode ficar, e não fica, sem resposta. Os exemplos a esse respeito são infinitos e fazem parte do dia-adia de quem trabalha com essa clientela. É facílimo demonstrar que um laudo psiquiátrico é uma colcha de retalhos de preconceitos; mas é uma questão difícil declarar que um homicida, com mais de uma dezena de assassinatos nas costas - ordenados por Deus e pelo diabo evidentemente -, não é alguém perigoso e soltá-lo. O que fazer, por exemplo, com alguém encontrado prestes a pular da ponte Rio-Niterói e que, interrogado sobre seu ato, não sabe dizer quem é, onde mora, como veio parar naquele local, e mesmo o que estava fazendo? Ou com aquele que se preparava para jogar um coquetel molotov na Câmara Municipal porque era dali que partiam as tramas para destruí-lo. Ou ainda, era alguém louco, completamente louco, mas seu pai o suportava e conseguia viver com ele e mesmo promover uma vida relativamente produtiva - pequenos serviços e responsabilidades. Bom, com a morte do pai... Enfim, quem quer que tenha uma inserção séria em instituições psiquiátricas reconhecerá nessas breves indicações o seu dia-a-dia e o impasse radical que tais situações representam e a necessidade de instrumentos para encaminhar a situação, coisa que a mera crítica não fornece 


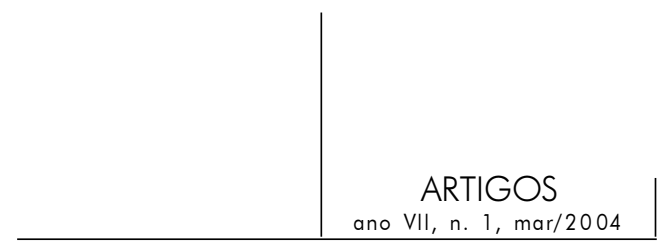

- isto é, se fazem necessários instrumentos próprios e específicos para além da crítica, que, como vimos, tem seu campo de efetividade próprio, que não coincide necessariamente com o ato especificamente clínico.

É bastante curioso que a análise crítica do discurso psiquiátrico em geral se detenha apenas nos textos, colocando entre parênteses as demandas e as circunstâncias concretas dessas demandas, bem como seus desdobramentos. Essa operação de ignorar as demandas e seus correlatos - pois é disso que se trata, de uma operação discursiva - faz mais do que introduzir um viés metodológico, uma divisão no campo fenomênico de um dado objeto de estudo - no caso, a "doença" mental. Essa operação privilegia a significação do texto psiquiátrico e no mesmo ato desconhece o real em relação ao qual esse texto está irremediavelmente mesclado. Essa disjunção entre a significação do dizer psiquiátrico e o real que ele tenta localizar chega mesmo ao limite de anulação do saber psiquiátrico ou de sua simplificação. Colocando de lado o real, o caminho está aberto para fixar a discursividade psiquiátrica numa significação negativa referida a um universo de discurso distinto do original, agora político ou ideológico. O louco passa a ser entronizado como figura de liberdade e a psiquiatria como o pólo repressor a serviço do poder e da ideologia dominantes. Dentro do mesmo processo chegamos também a uma pedagogia psiquiátrica quando então os sujeitos se reconhecem como "portadores de transtornos" e buscam no saber psiquiátrico o reconhecimento de seu sofrimento. Essa visão das coisas, evidentemente falsa, sustenta-se por si só. E boa parte das discussões atuais nesse campo são pseudodiscussões: trata-se apenas de acionar um esquema de compreensão, do bem contra o mal e esperar que a histeria reinante cooptada por uma drogadicção generalizada faça o resto.

$\mathrm{O}$ encaminhamento freudiano na cultura rompeu radicalmente com os princípios norteadores da acepção comum de que há um saber em algum lugar, e que nos desenvolvemos para apreendê-lo por meio de nossas funções mentais. A pesquisa freudiana desvela a suposição básica de nossa psicologia de que há Um, alguém em algum lugar, que sabe sobre nós. Falar é, portanto, atualizar essa suposição a cada momento, assim como seus limites, e é isso que faz retorno sobre a psicologia cotidiana e torna possível uma apreensão psicopatológica das funções mentais (pensamento, percepção, memória, inteligência, afetividade) como funções no discurso. A psicopatologia cotidiana não é uma psicologia desviada, que é a maneira mais comum de entendê-la, mas sim o que há de mais próprio na junção entre corpo e linguagem. A crítica à psiquiatria parece não levar isso em conta, ao contrário, parte do princípio de que há Um que já demarcou o terreno do bem e do mal, do normal e do patológico.

Como já vimos, a crítica teve uma importante vitória que deve ser devidamente situada. De fato, o diagnóstico pode se reduzir a uma rotulação 


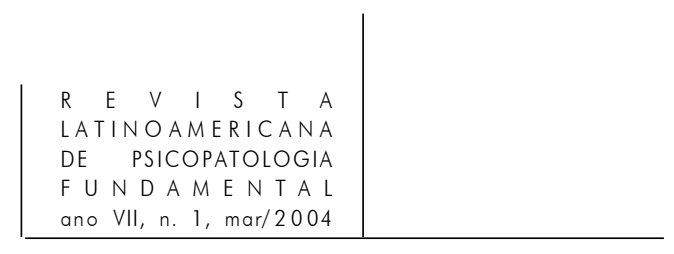

“marginalizante", mas isso só acontecerá se justamente a psiquiatria ignorar seu fundamento social. Ora, por efeito dessa própria crítica, é essa determinação mesma que passa a freqüentar o campo psiquiátrico que, desse modo, pode retomar sua tarefa identificadora com muito mais pertinência e propriedade. Mas eis que para nosso espanto, vemos com freqüência a critica degradar-se em criticismo, isto é, ela assume uma pretensão totalizante que extrapola seu escopo próprio, ela não se contenta em revelar o componente social do ato psiquiátrico (o que é sua função própria), ela passa a desqualificar esse ato em si mesmo, como se fosse por ele e a partir dele que surgisse a questão da loucura. Como toda extrapolação somos lançados no absurdo, já que é uma tolice supor que é o psiquiatra quem inventa a loucura, ou seja, a própria crítica que deveria revelar o caráter social da loucura acaba por negá-lo ao desconhecer a determinação social que age para que a questão da loucura seja assumida concretamente por uma sociedade por intermédio de uma ordem institucionalizada como a psiquiatria afinal de contas, é o que queremos dizer, os psiquiatras não inventaram a si próprios, eles são tão efeitos sociais quanto a loucura. Por isso, insistimos, o excesso crítico não trabalha a favor do sujeito, já que ele é uma demissão da tarefa de se demarcar uma discursividade Outra, no caso a do psicótico, em relação ao discurso comum ou normal. Se nos detivermos no trabalho dos psiquiatras clássicos, veremos ali o trabalho meticuloso de isolamento de uma estrutura problemática com suas variantes no automatismo mental, nos delírios sistematizados, nas psicoses alucinatórias, nas paranóias, nas parafrenias, na melancolia, na Síndrome de Cotard, na de Serieux e Capgras, entre inúmeras outras. Quem triunfa no "apagamento" das distinções é o imperialismo do discurso comum. Não havendo reconhecimento da psicose, não há distinções a fazer; não há, por conseguinte, direções de tratamento específicas. É a "geléia geral", cuja medida comum é uma suposta normalidade não mais universal, mas consensual. Em relação a esta, os desvios são entendidos ou como fundamentados em problemas cerebrais - fatos extradiscursivos - ou como problemas de "aprendizagem" - problemas passíveis de se dobrarem a algum tipo de "negociação" - das técnicas de programação neurolingüística a todo tipo de psicoterapia, chegando aos direitos das minorias. A vitória foi então a de que o "discurso comum", o discurso mais submetido aos agenciamentos do poder, o discurso que afirma uma racionalidade abstrata e geral, apagou as marcas de algo que poderia indicar uma posição exterior ao discurso da Razão. A vitória foi contra o poder da transferência, em última instância o poder da palavra, no qual aos mestres se substituíram os cientistas. Critica-se e ataca-se o arbítrio dos mestres, mas não se fala muito a respeito da palavra absoluta, inquestionável, do cientista que, em sua neutralidade e imparcialidade, diz o real, para além e aquém de qualquer subjetividade interessada. Qual o lugar para o sujeito e o desejo numa determinação que se ancora na 


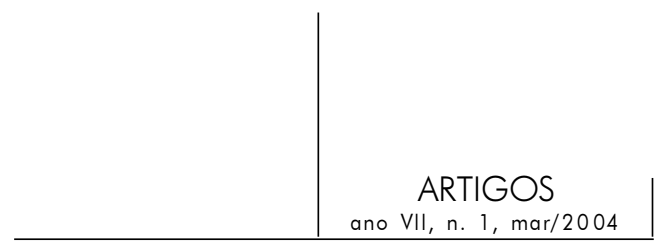

química? Ou na gestão do consenso social? É uma vitória monumental, já que ela é apregoada, cantada, justamente por aqueles que se diziam críticos do poder, daqueles que levantaram suas vozes contra o arbítrio do poder.

É bom que se lembre que a situação dos marginalizados não mudou nenhum milímetro com tal remanejamento das categorias no plano da ideologia. É esse fato, aliás, que faz aparecer o equívoco do criticismo e o papel que ele verdadeiramente acabou por desempenhar: a de submeter toda a reflexão sobre os homens que antes estava na mão dos padres, dos moralistas, dos médicos, dos filósofos, dos juristas, dos artistas e poetas, deles próprios (já que no fundo eles eram moralistas), etc., à lógica da ciência, aos especialistas. O discurso comum cada vez mais se afasta de suas fontes tradicionais, transmitidas pela palavra e a transferência e, cada vez mais, afirma o ponto de vista desses especialistas. Esse remanejamento categorial conta com um marketing poderoso, já que sua fundamentação científica sempre faz apelo ao progresso, ao conforto, à racionalização dos custos e a todo tipo de vantagem. Não se dão conta de que, com isso, o que temos é a submissão da fonte de todas as lógicas - a linguagem natural - a uma lógica específica dela derivada, que é a lógica da ciência, isto é, para sermos bem precisos, a teoria dos conjuntos e a lógica de predicados de $1^{\text {a }}$ ordem. Um exemplo especialmente claro dessa estratégia encontramos justamente no pragmatismo. Com seu horror ao absoluto - de fato, ao desejo -, seu apego ao relativismo só faz afirmar, no campo social, com maior ou menor "inocência", a categoria abstrata de classe (por exemplo, as minorias são classes) como a categoria em jogo na base da organização social. Todo movimento é então concebido dentro da visão abstrata do jogo de relações estipulados por essas teorias formais e lógicas. Pergunta que deixamos no ar: de que adianta o relativismo, que em geral sempre se situa no plano semântico, na detração de toda significação absoluta e universalizante como fonte do arbítrio do poder, se, no plano lógico, no plano formal, temos uma operacionalização dos jogos de linguagem, da interação humana, que é absolutamente coerente - isto é, no plano da sintaxe - com todas as formas de exploração do homem pelo homem encetada pelo capital? Neutraliza-se o desejo para produzir a escravidão moderna que pode ser, aliás, bem confortável. Tradicionalmente, era a escravidão que poderia vir a matar o desejo, o que não é verdadeiro, já que muitas revoluções foram forjadas no seio de regimes escravocratas. Atualmente, a escravidão é "facilitada" pela neutralização do desejo efetivada pela ciência, podendo ser, como já dissemos, algo bem confortável, até mesmo no sentido de produzir uma intensa sensação de liberdade - pois é disso que se trata em nosso mundo: prender as pessoas ao consumo de sensações.

Mas retomemos o tema da psicose, com vistas a pensar sua particularidade para proporcionar a esses sujeitos melhores condições para encaminharem 


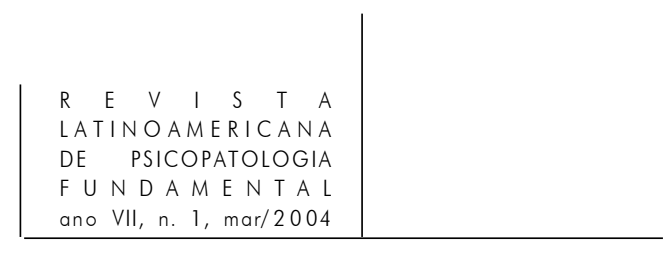

suas vidas. Aliás, esse nosso desenvolvimento se esclarece bastante com base nessa palavra "particularidade": a psicose representa uma estrutura clínica específica. Para nós, a psicanálise tem êxito no ponto em que os clássicos, de uma certa forma, fracassaram em situá-la no nível do conceito em seu campo próprio: o da linguagem. Verdade seja dita, foi com a clínica que eles estabeleceram que praticamos ainda hoje - ainda que isso não seja admitido ou reconhecido. Podemos talvez afirmar que fracassaram em suas explicações, mas não no que apreenderam da estrutura. Por isso, não há como considerá-los como ultrapassados no desenvolvimento de nossa ciência. Na verdade, eles fundaram a clínica que seguimos até hoje, só que o fazemos de forma disfarçada, sem pagar o tributo transferencial a essa filiação, o que implica reconhecer que existimos numa cadeia simbólica estabelecida por Pinel, Esquirol, Falret, Griesinger, Charcot, Clerambault, Jaspers, Freud, Lacan e vários outros ${ }^{1}$ (aliás, muito pouco se lê de Lacan psiquiatra e de suas contribuições). Dessa clínica é possível afirmar a unidade de estrutura do campo das psicoses. Falamos de "fracasso" dos clássicos porque assistimos a uma desistência da psiquiatria em relação a afirmar essa unidade. ${ }^{2}$ A clínica deles era sobretudo descritiva - estando bem longe, porém, da pobreza descritiva praticada hoje em dia, que não denota um verdadeiro trabalho de conjugação clínica. Do ponto de vista da ciência, esse trabalho descritivo poderia ser visto como algo mesmo esperado por parte das ciências dos neurônios e das objetivações psicologistas (por exemplo, psicologia da cognição), uma espécie de etapa preliminar. A partir dele seria possível para as ciências biológicas e cognitivas as decisões quanto às possíveis unidades estruturais que organizariam as diversas síndromes entre si. Realizado esse programa, a função da psiquiatria então acabou por se reduzir. Hoje, por seu empirismo sistemático, ela apenas sanciona os desvios em relação ao campo da realidade, porque situa o campo da efetividade determinativa não na linguagem nem em sua armadura significante fundamental - o discurso -, mas ou num suposto real da matéria viva - os neurônios - ou na perspectiva de tomar o que desde sempre esteve referido de alguma forma à subjetividade como se fosse uma máquina. A analogia com os computadores promovida pelas psicologias cognitivas é equivocada (os psicólogos cognitivistas em geral desconhecem o fato que as referidas máquinas são

1. Poder-se-ia estranhar os nomes de Freud e Lacan nessa série. O de Lacan, contudo, é mais óbvio: de fato ele foi um psiquiatra que nunca abandonou essa referência, mesmo avançado em sua formulação psicanalítica. Quanto a Freud, não podemos esquecer que ele sempre considerou em sua discussões clínicas o ponto de vista dos psiquiatras de sua época, o que faz com que muitos de seus textos tenham mesmo o carácter de uma discussão psiquiátrica.

2. A unidade do campo das psicoses é uma tese clínica que retomaremos num outro trabalho. 


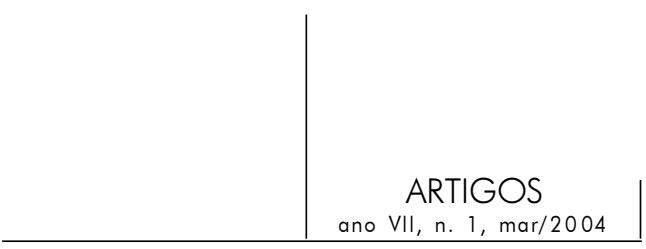

justamente matemática cristalizadas em coisas; os computadores são implementações formais coerentes com a lógica de $1^{\text {a }}$ ordem e a teoria dos conjuntos).

É nesse nível que a psicanálise pode aportar algo importante para a psiquiatria. Ela pode representar a chance para esta última de entender a psicose a partir de sua unidade fundamental. Eis uma hipótese fértil que pode introduzir orientações importantes e concretas para a clínica: a da unidade do campo psicopatológico com base em estruturas clínicas específicas, que dizem respeito ao fato de o homem ser uma criatura que fala.

\section{Psicanálise e psicose}

A clínica psicanalítica opera um deslocamento fundamental em relação à clínica psiquiátrica, o que permite uma formulação mais pertinente acerca do espaço no qual devemos situar o conjunto das manifestações da subjetividade humana. Como indicamos, as demandas sobre a clínica psiquiátrica, que a estabelecem como tal, originam-se nas pressões que atingem o campo da realidade e nos riscos que a ruptura desse campo traz em termos da passagem ao ato. Já a psicanálise é uma clínica formada baseando-se na escuta das narrativas que os pacientes fazem sobre suas vidas e dificuldades em vivê-la. Ela não está confrontada com uma pressão inadiável em direção à motilidade e, mais do que isso, seu modo operatório opõe-se, por princípio, à ação motora. Em que pese o sofrimento do sujeito, Freud sugeria-lhe que aguardasse e se pusesse a falar e que seria no exercício dessa fala que ele encontraria alívio e/ou solução para seus sofrimentos e sintomas. Observa-se desse modo, como é dito por todos à exaustão, que a clínica de Freud é antes de tudo orientada para e pela palavra o tema do ato é um tema limite. Sua hipótese inicial, ainda junto de Breuer, embora nem sempre isso fosse claro ou explícito, é a de que a subjetividade é regida por leis semelhantes às dos demais sistemas biológicos - suas explicações fisicalistas naquele momento corroboram esse ponto de vista. A vida representativa dos sujeitos, povoada de elementos "linguageiros", realiza um certo tipo de "metabolismo" ou de trabalho de equilibração. Esses mecanismos de regulação podem se quebrar ou funcionar mal. Inicialmente, a psicoterapia proposta por Freud e Breuer (principalmente este último) visava restabelecer uma suposta normalidade na vida psíquica, entendida como sistema biológico, isto é, visava à adaptação, pela intervenção nos mecanismos de equilibração.

Gradativamente, principalmente a partir de 1895, Freud vai se compenetrando de que o que está em questão nas diversas afecções mentais não é alguma coisa que se deixa apanhar em sua inteligibilidade pela referência a sistemas biológicos 


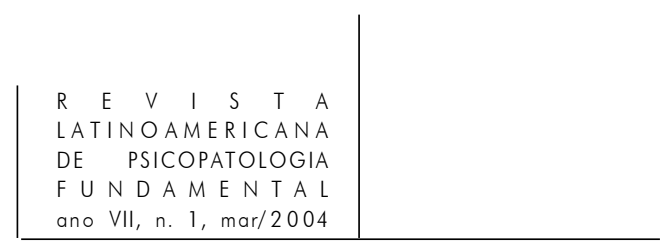

- por mais amplos que estes possam ser entendidos e aplicados. Ele vai se apercebendo de que o que está na base das neuroses é a "máquina" de significar as coisas ela própria. Sabemos os termos da direção assumida por Freud: a linguagem, a "máquina" de significar, não pode ser pensada sem seu contato com o corpo, com base no qual o sujeito aparece como desejo. Não sendo mais o corpo neutro, unidade físico-química natural da biologia, mas o corpo que deseja esse corpo é para Freud, então, o corpo erotizado, sexuado.

Baseando-se no fato de ser uma prática de discurso, cujos efeitos são entendidos com base na efetividade própria dessa ordem, a psicanálise entende inúmeros atos humanos, muitos dos quais sintomáticos, mudos, a partir de princípios que dizem respeito à linguagem e seu funcionamento; esses são atos significantes. A incidência do entendimento psicanalítico para a psiquiatria significa, sobretudo, que os eventos, as urgências referentes a esta última, podem ser entendidas também com base na referência à linguagem e ao discurso. Esse entendimento, de imediato, não muda muito as exigências e responsabilidades da psiquiatria. A iminência da passagem ao ato, por exemplo, não é menor por conta de podermos entendê-la em função da linguagem, e não em função de qualquer desvio neurofisiológico. É bastante provável que, no auge de uma crise aguda, não seja possível nenhum tipo de intervenção que encaminhe as coisas para o discurso: o paciente terá de ser contido, medicado e coisas afins. Para muitos casos, uma ação terapêutica orientada para o discurso tem muito mais um caráter de aposta do que propriamente de um procedimento efetivo. É o caso dos autistas, dos pacientes "demenciados" já afetados pela senilidade, muitos esquizofrênicos crônicos, etc. O caso do paciente encontrado na ponte RioNiterói, por exemplo, com ele não foi possível durante algum tempo qualquer manobra de linguagem; teve-se que esperar algumas semanas até que ele balbuciasse algumas palavras a partir das quais fosse possível localizar sua família. Mesmo quando consideramos o tratamento em vez das intervenções nas crises agudas, é bom sermos cautelosos e modestos quanto às promessas de uma abordagem psicanalítica strictu senso, isto é, centrada na palavra, que possa produzir resultados efetivos. Não são poucos os casos que, pelas mais diversas razões, são inacessíveis a qualquer tipo de abordagem - inclusive às medicamentosas -, quanto mais à psicanálise. É óbvio que estamos nos referindo à clínica da psicose maciça, isto é, aquela verificada nos grandes hospitais, ambulatórios e afins, em geral públicos. Não estamos discorrendo sobre uma clínica da psicose mais estrita, que se define a partir de uma seleção daqueles pacientes - poucos, se considerarmos a população total atendida nos centros citados acima -, que se adaptam ao consultório particular, embora sejamos da opinião de que essa clínica mais estrita seja da maior dignidade e aporte referências valiosas para o trabalho mais amplo na cena pública. 


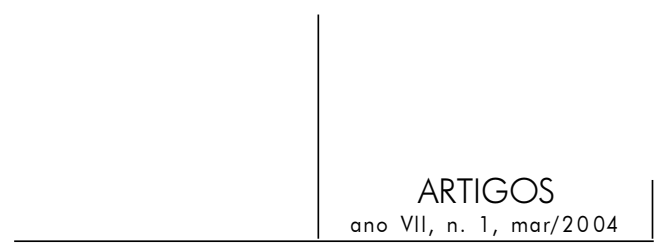

De qualquer modo, do fato de o entendimento psicanalítico - como, aliás, qualquer outro - ter uma efetividade relativa não podemos deduzir muito com respeito à sua relevância ou não. Isto porque, como já deixamos claro, via de regra a psicose resiste a qualquer tratamento. Essa afirmação é tão mais verdadeira quanto mais se conceba a cura como uma espécie de restauração do campo da realidade. E é a respeito desse ponto que a psicanálise é um divisor de águas.

Muito concretamente, de onde a psiquiatria tira sua autoridade para intervir? Se simplesmente a situamos do lado da medicina, a resposta é simples e rápida. Ela tem um mandato que a situa em referência às exigências da ordem social, no sentido da funcionalidade desta. Lacan não hesitaria em alocar a medicina como um estamento discursivo visando ao bom funcionamento das coisas; isto é, em sua esfera de ação, ela representaria o que ele designa como discurso do mestre. ${ }^{3}$ Mas seria esse o caso da psiquiatria? A resposta a esse respeito não pode ser unívoca; temos aí, com efeito, um campo de intervenção problemático - e que, a nosso ver, deve continuar assim. Por quê? Porque no plano de querer-que-ascoisas-funcionem, ${ }^{4}$ o psiquiatra, como médico, não pode evitar que, em inúmeras situações, sua operação se dilua numa mera manobra de poder, já que o poder, justamente, de todas as iniciativas humanas é a que se situa por excelência no plano de-querer-que-as-coisas-funcionem - com freqüência custe o que custar. Podemos dizer que a política e todos os seus instrumentos, principalmente os de força, têm como referência básica, ao menos implicitamente, esse custe-o-quecustar, que em seu limite nada mais é do que a restrição máxima do sujeito, podendo chegar, inclusive, à sua abolição simplesmente. Há uma distinção a fazer entre uma vontade-de-que-as coisas-funcionem exercida a partir de um ethos que a legitima em seus atos e, nesse sentido, dá espaço para o sujeito e uma vontadede-que-as-coisas-funcionem à revelia do sujeito. Freqüentemente, como nas situações que envolvem conflitos, em praticamente todo tipo de disputa, a solução buscada é a de uma ação que, ao se afirmar, implica a anulação, ou uma séria restrição à subjetividade de outrem.

Não vamos nos estender muito na temática sobre as implicações das ações humanas nos laços sociais. Nosso propósito é o de lançar luz à função da psiquiatria com base em um entendimento psicanalítico de sua inserção social. Consideramos ser suficiente limitarmo-nos a uma compreensão geral do fenômeno do poder, para localizarmos o ponto de incidência da psiquiatria, bem como sua

3. Charles Melman, em seu seminário sobre a neurose obsessiva, a aloca sob essa rubrica.

4. Quando unimos por hífen várias palavras, queremos indicar algo um pouco mais forte do que a descrição de um estado de coisas, apontamos para algo da ordem de um conceito. 


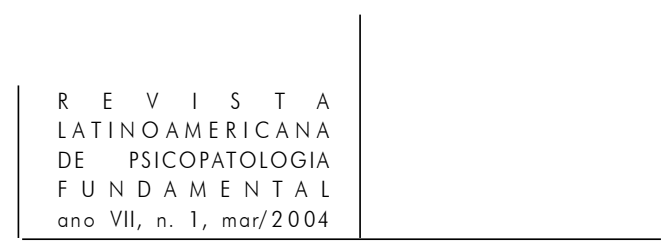

função. Por exemplo, não é o caso de entendermos que uma vontade-de-que-ascoisas-funcionem, implicando uma restrição ao sujeito, é necessariamente um mal. Por meio do Estado, os homens tendem a concordar que é legítima a restrição da subjetividade de alguém cujo modo de freqüentar os laços sociais é o de impor restrições às subjetividades de seus semelhantes, de maneira arbitrária, visando tão-somente à própria satisfação. É o caso, por exemplo, de um homicida, de um estuprador. Em casos como esses, as pessoas em geral estão de acordo que se restrinja a ação do sujeito disposto a tais atos. Toda a necessidade do direito iniciase com a questão a respeito do alcance que cada sujeito, cada um de nós, tem de determinar a extensão e o modo próprio de gozo, seu próprio usufruto, do corpo de seu semelhante ou de coisas que pertencem a ele de maneira essencial. A problemática do crime e, conseqüentemente, a necessidade do direito penal nas sociedades modernas está afeita a esse tipo de consideração.

Em relação ao crime, temos que, embora se imponha ao sujeito uma restrição à sua subjetividade na forma da pena, não se lhe caça a palavra, isto é, pelo menos em tese, ele é alguém que, como sujeito, faz-se representar. Não é esse o caso da psicose, em que o psiquiatra como médico, principalmente levando em consideração as teorias que informam a psiquiatria contemporânea, encontra o móvel das ações não na relação palavra/subjetividade, mas num substrato determinativo extra-subjetividade, extralingüístico, que é o cérebro, ou a cognição considerada num nível de "operatividade" análogo a processamentos computacionais "a-subjetivos". Não nos parece muito diferente uma outra orientação psiquiátrica que chamaríamos "social". Aí também a subjetividade reconhecida é expressão cultural, é manifestação e resposta a fatores externos ao sujeito e mesmo palco, cenário, de conflitos entre a liberdade individual e a coerção da cultura. Não está em questão para nós a efetividade ou eficácia da redução operada pela psiquiatria, mas seu sentido no campo do discurso e deste discurso em particular que toma para si a exigência de que as coisas têm de funcionar. A psiquiatria subtrai do campo da palavra/subjetividade a loucura, seja pela abolição, seja pela normalização. Vale dizer, a psiquiatria torna-se um agente importante no sentido de diminuir o tamanho da área onde o sujeito pode se exercer pela palavra, pelo o que tem a dizer. É importante ressaltar que os instrumentos psiquiátricos tomados em si mesmos não têm poder de calar a loucura como uma autêntica manifestação humana, isto é, não são esses instrumentos que reduzem o campo do sujeito. Mais uma vez, o que reduz o campo do sujeito é o discurso que, apoiando-se na efetividade dos instrumentos extra-subjetivos que operam no real da bioquímica cerebral ou das relações sociais, reduzem a loucura a uma espécie de invasão desse real no campo da subjetividade, invasão que tem o poder de anulá-la como potência inerente ao homem, porque ali onde o sujeito poderia advir se situa a coisa molécula, enzima, enfim, coisas por definição mudas ou 


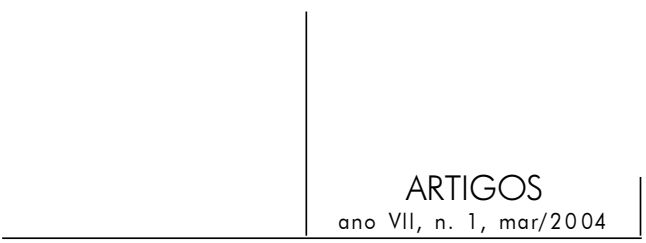

procedimentos interpretativos de normalização, em que o louco é visto como tela vazia e passiva à recepção dos mandamentos do bom funcionamento social.

Para nós, não se trata simplesmente de denunciar a manobra da ciência no sentido de, pela psiquiatria, avançar na exclusão do sujeito. O ponto decisivo é o dos móveis dessa resposta. A psiquiatria opera nessa direção ditada pela ciência por não poder tolerar qualquer outra relação do sujeito com a linguagem a não ser aquela na qual o sujeito identificado a seu "eu", poderíamos até dizer, alienado em seu "eu", concebe-se como pequeno mestre do que diz. E que, por sua vez, tal qual pequeno mestre concorda em limitar seus apetites ao escopo do que lhe é oferecido, sendo justamente esse se limitar ao escopo do que é oferecido, estar inserido no campo da realidade sem maiores problemas do que aqueles ordinários, isto é, os pequenos dramas nos quais o que está em jogo é meramente o transitar entre as ofertas possíveis que a sociedade capitalista oferece. O que não se admite então é qualquer resposta que interrogue essa modalidade de relação com a linguagem.

Mas não se conclua daí que supomos ser o psicótico alguém revolucionário, alguém cuja resposta específica visa interrogar a ordem social em seus fundamentos. Ora, se fosse esse o caso, nada distinguiria o psicótico do indivíduo normal: alguém que, de posse de seu autodomínio, interrogaria a ordem social. Esse seria o caso, como já falamos, do revolucionário, e não do psicótico. É importante constatarmos que a avaliação de psicose é solidária da intervenção psicoterapêutica no sentido de que é nessa intervenção que se reconhece o funcionamento psicótico, é com base nessa intervenção que se parte para um modo de recepção da psicose que amputa esse sujeito e sua reposta característica, de sua inserção na esfera da subjetividade. O psicoterapeuta apenas modula a linguagem comum no sentido de empobrecê-la, de articulá-la em demandas mais primárias para tentar, por essa via, rearticular o sujeito psicótico ao modo ordinário de funcionamento da linguagem. É no fracasso disso que se passa aos procedimentos propriamente biológicos. Em geral, o par psiquiatra biológicopsicoterapeuta estão sempre juntos. Ali, onde a linguagem quase totalmente reduzida a um conjunto de comandos agenciados de uma forma tão benévola quanto "infantilizante" fracassa, a ação dos medicamentos far-se-á presente. Não importa que aparentemente o psicoterapeuta, para operar, tenha de supor um sujeito apto a freqüentar a linguagem pelo menos num nível elementar. Essa suposição de sujeito só se mantém enquanto referida ao paciente, pelo menos potencialmente no sentido de poder ser tomado pela mestria usual da língua, mas assim que o paciente dá sua resposta propriamente psicótica, que nem precisa ser muito disruptiva, é aos medicamentos que se recorre. Desde que o paciente proponha um ato enigmático, isso é suficiente para que todos se perturbem, e 


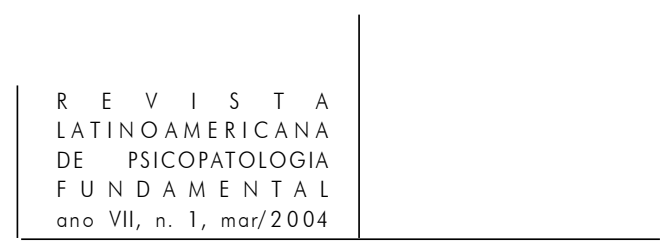

a velha descrença na palavra ressurja com toda sua força: se o psicótico não fala como nós falamos, então... ele sequer fala. Vale dizer, a bondade do psicoterapeuta, sua indulgência, sua paciência para com o psicótico é apenas tácita. Ela visa sobretudo a recapturá-lo num modo de dizer que é o único que ele concebe e que é tão imperativamente interno à vontade-de-que-as-coisasfuncionem quanto o "biologismo" médico. É tão restritivo para a subjetividade quanto as enzimas e os neurotransmissores, posto que só admite o sujeito desde que esteja conforme a sintaxe e a semântica ordinárias. A benevolência do educador aqui esconde seu autoritarismo tirânico, ao contrário, curiosamente, do psiquiatra biológico, que visivelmente opera baseando-se em um instrumento - o medicamento - exterior à palavra.

Eis então a relevância da psicanálise para a psiquiatria. Esta insiste em que há um dizer propriamente psicótico; que não obedecer à gramática e à semântica não é estar determinado por algo cuja incidência seja extra-subjetiva. Ao contrário, um dizer próprio da psicose pode ser discernido no disparate mesmo de sua fala louca. A psicanálise reconhece que não é um sujeito identificado a seu "eu" quem fala, ela concorda que quem fala seja uma coisa, mas não uma coisa "neurônio" - química, não-subjetiva. Quem fala é uma coisa que suporta a alteridade fundamental da linguagem, que é inaugural para a subjetividade como tal.

A psicanálise então permite uma outra possibilidade de laço com a loucura ao concebê-la como uma estrutura particular, o que, no entanto, não libera a psiquiatria de nenhuma responsabilidade diante das demandas que se dirigem a ela. A novidade é que, podendo situar as coisas em seus devidos lugares, principalmente reconhecendo os limites da psicose implicados em sua especificidade, ela pode propor agenciamentos mais plausíveis para a loucura, em vez de calá-la, quer pela droga, quer por uma pedagogia que a situa como uma variante da debilidade mental.

\section{Referências}

Cavalcanti, M. T. \& Bettencourt, C. Pode um psiquiatra deixar de ser psicanalista?. Cadernos do IPUB, Rio de Janeiro, n. 5, p. 199-216, 2000.

Czermak, M. Patronymies. Considérations cliniques sur les psychoses. Paris: Masson, 1998.

Paixões de objeto. Estudo psicanalítico das psicoses. Porto Alegre: Artes Médicas, 1991.

Fernandes, F. L. F. Sobre a passagem ao ato. In: Circulação psicanalítica. Rio de Janeiro: Imago, 1992, p. 230-9. 


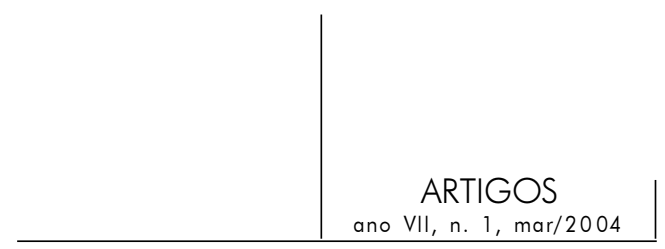

Figueiredo, A. (org.). Psicanálise - Pesquisa clínica. Rio de Janeiro: Edições IPUBCUCA, 2001. (Coleções IPUB.)

Melman, C. Estrutura lacaniana das psicoses. Porto Alegre: Artes Médicas, 1991.

Les paranoias. Le discours psychanalytique, n. 21, p. 7-15. Paris: Revue de la Association Freudienne Internationale, fev./1999.

Rocha, A. C. C. Dos conceitos freudianos ao objeto da psicanálise. Tempo Freudiano - O Seminário de Lacan: travessia; Os quatro conceitos fundamentais da psicanálise, Rio de Janeiro, n. 1, p. 171-92, maio/2002.

Ética e assistência. In: Ética e saúde mental. Rio de Janeiro: Topbooks, 1996, p. $85-101$.

Silva Filho, J. F. A teoria necessária para o enfrentamento dos problemas da Saúde Mental. Anais do XIX Congresso Brasileiro de Psiquiatria. Recife, 2001.

TenóRIo, F. A psicanálise e a clínica da reforma psiquiátrica. Rio de Janeiro: Rios Ambiciosos, 2001.

Thierry, J. \& Czermak, M. (org.). Journal Français de Psychiatrie, n. 8. Paris: Editions Erès, 1999.

Este trabajo discute los aspectos en los cuales el psicoanálisis puede ser relevante en el campo de la salud mental y de la psicopatología. Conducimos nuestra discusión a partir de un tratamiento "con éxito" para, después, llevar en consideración las propuestas clínicas y de gestión de la "enfermedad mental” ora informadas por el sociologismo ora por el biologicismo de la psiquiatría contemporánea. Interrogamos la curiosa alianza entre esas formas de comprensión clínicas bajo el prisma de la exigencia en comprometer los resultados del tratamiento de la enfermedad mental a una inserción pacífica del sujeto a formas más tolerantes de gestión social - ambientes artificiales de convivencia -, todo esto en detrimento de una escucha efectiva del decir psicótico, en la cual se neutraliza la verdad que ese decir puede vehicular. Nuestra orientación es la de que el psicoanálisis es una discursividad comprometida en recoger y hacer reverberar ese decir de la locura en el orden del discurso.

Palabras clave: Psicosis, psiquiatría, salud mental, reforma psiquiátrica

Le présent travail examine dans quelle mesure la psychanalyse peut se révéler pertinente en matière de santé mentale et de psychopathologie. Nous avons conduit notre discussion sur la base d'une cure "réussie" pour prendre ensuite en considération les propositions cliniques et de gestion de la "maladie mentale", qu'elles 


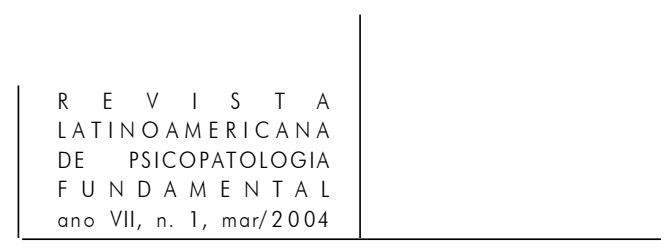

soient faites par le sociologisme ou par le biologisme de la psychiatrie contemporaine. Nous avons interrogé l'alliance surprenante entre ces appréhensions cliniques $d u$ point de vue de l'exigence de compromettre les résultats du traitement de la folie au nom d'une insertion pacifiée du sujet selon des modes plus tolérants de gestion socialemilieux artificiels de convivialité -, cela au détriment d'une écoute effective du dire psychotique dans laquelle se neutralise la vérité que ce dire peut véhiculer. Notre orientation est que la psychanalyse est une discursivité engagée à recueillir et faire résonner les paroles psychotiques dans l'ordre du discours.

Mots clés: Psychose, psychiatrie, santé mentale, réform psychiatrique

This article discusses in what aspects psychoanalysis might be relevant in the field of mental health and psychopathology. The article begins with a "successful" treatment of a psychotic patient and goes on to consider clinical and administrative proposals regarding "mental illness" whether from the sociological or the biological point of view in contemporary psychiatry. We also discuss the curious alliance between these clinical understandings based on the need to verify the results of the treatment of madness by placing the subject into more tolerant forms of social organization. All of this is in detriment to true listening to what the psychotic is saying, where the truth that his or her discourse might say is neutralized. The position taken here is that 62 psychoanalysis is a discourse committed to accepting the discourse of madness and make it reverberate.

Key words: Psychosis, psychiatry, mental health, psychiatric reform

Versão inicial recebida em setembro de 2003

Versão revisada recebida em novembro de 2003 